\title{
Osteonecrose da mandíbula em paciente portador de mieloma múltiplo - patologia secundária ao uso do pamidronato
}

\author{
Jaw osteonecrosis in a patient suffering from multiple myeloma - pathology secondary to \\ pamidronate therapy
}

Andréia C. Melo ${ }^{I}$

Marcos Bastos ${ }^{2}$

Maria R. Bastos ${ }^{2}$

Adrieli S. Loureiro ${ }^{2}$

Sérgio S. Araújo ${ }^{2}$

\begin{abstract}
Descreveremos a ocorrência de osteonecrose da mandíbula associada ao uso de pamidronato (Aredia) em uma paciente portadora de mieloma múltiplo. Apesar de não ser possivel provar definitivamente a associação entre a terapia com bisfosfonatos e a ocorrência de osteonecrose da mandibula, a associação entre mieloma múltiplo, imunossupressão grave, terapia prolongada com bisfosfonatos e a localização peculiar na mandibula sugerem tal ocorrência. Os hematologistas devem estar atentos a essa séria complicação nos pacientes com mieloma múltiplo que recebem tratamento prolongado com pamidronato. Rev. bras. hematol. hemoter. 2005;27(3):221-222.
\end{abstract}

Palavras-chave: Mieloma múltiplo; osteonecrose da mandíbula; pamidronato.

\section{Introdução}

O mieloma múltiplo é uma doença imunoproliferativa das células plasmocitárias, cujo tratamento pode incluir a quimioterapia, o uso de agentes antiangiogênicos, imunomoduladores e o transplante de medula óssea. A administração mensal de bisfosfonatos aumenta a sobrevida e a qualidade de vida dos portadores de mieloma. ${ }^{1}$ A osteonecrose da mandíbula pode ser induzida por radioterapia, infecções e determinadas drogas. ${ }^{2}$ Descreveremos o caso de uma paciente com mieloma múltiplo que desenvolveu osteonecrose da mandíbula provavelmente relacionada à terapia com pamidronato.

\section{Relato de Caso}

Paciente VSC, sexo feminino, 46 anos, diagnóstico de mieloma múltiplo há 7 anos (tipo Bence Jones puro, cadeia leve tipo $\lambda$ estádio III A). Recebeu inicialmente oito ciclos de vincristina, adriamicina, e decadron (VAD - dose total) juntamente com infusões mensais de pamidronato (Aredia) $90 \mathrm{mg}$ a cada trinta dias, atingindo a fase estável. Foi submetida ao transplante medular autólogo em março de 1999. Quando da recaída, em fevereiro de 2002, foram iniciados talidomida $400 \mathrm{mg} /$ dia e interferon 3.000.000 U/dia, três vezes/semana. Recebeu ainda ciclofosfamida semanais e novos ciclos de VAD na tentativa de recolocar a doença em fase estável entre janeiro de 2003 e julho de 2004.

Aproximadamente cinco anos após o início da terapia mensal com bisfosfonatos, a paciente queixou-se de intensa dor de dente e mandibular à direita, trismo, disestesia e halitose.

Encaminhada ao odontologista, foi avaliada diversas vezes, submetida a extrações dentárias, recebeu vários cursos de antibióticos sem melhora. O exame da cavidade oral mostrava ulceração e necrose da mucosa bucal adjacente às áreas de exposição óssea, edema e descarga purulenta (infecção secundária), além da presença de fístula odontofacial à direita. A radiografia panorâmica da mandíbula mostrou área extensa sugestiva de necrose óssea com radiopacidade irregular (Figura 1).

Diante do diagnóstico de osteonecrose da mandíbula, o tratamento com pamidronato foi interrompido e a paciente recebeu opióides para controle da dor.

\footnotetext{
${ }^{2}$ Hematologistas do Hospital Governador Israel Pinheiro - IPSEMG.

Correspondência para: Andréia Cristina de Melo

Rua Álvares Maciel, $n^{\circ}$ 481, Apto. 07 - Bairro Santa Efigênia

30150 - 250 - Belo Horizonte- $M G$

Tel.:(0xx)31 3241-3917 - (0xx)31 9144-9489

e-mail:melo.andreia@uol.com.br
}

${ }^{l}$ Médica Residente de Clínica Médica do Hospital Governador Israel Pinheiro - IPSEMG. 


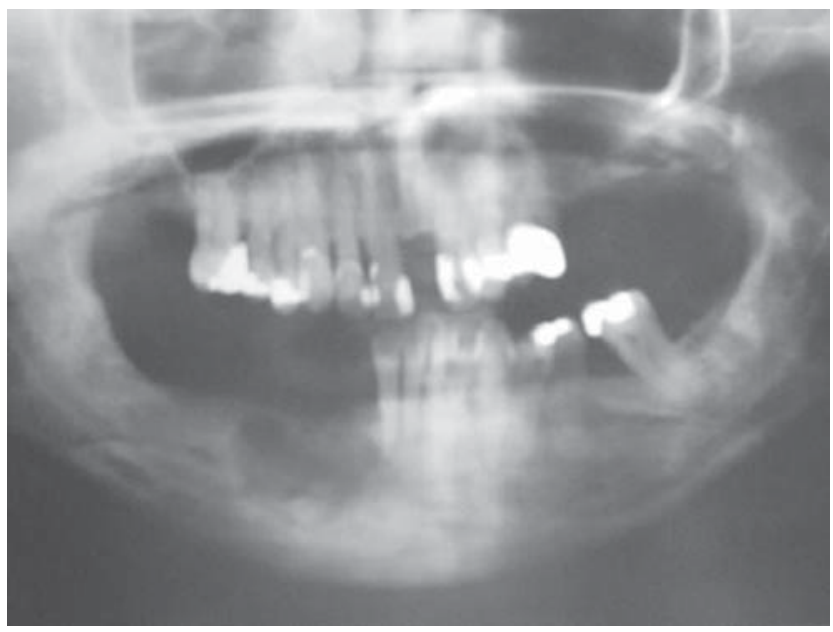

Figura 1. Radiografia panorâmica da mandíbula

\section{Discussão}

Várias estratégias podem ser aplicadas nos pacientes com mieloma múltiplo para minimizar as complicações observadas na doença. Importantes avanços incluem a prevenção e o tratamento da hipercalcemia e das lesões ósseas, o controle da dor e, em alguns casos, a diminuição na incidência de fraturas patológicas com a administração mensal de bisfosfonatos endovenosos. Essas drogas ligam-se avidamente às lacunas de absorção óssea e, por não serem metabolizadas, altas concentrações são mantidas nos ossos por longos períodos, sendo internalizadas pelos osteoclastos, inibindo a reabsorção óssea. O mecanismo exato de inibição dos osteoclastos ainda não foi completamente elucidado, mas o bisfosfonato parece ter também um efeito antiangiogênico. ${ }^{2,3}$

Os bisfosfonatos fazem parte de uma classe de medicação capaz de modificar a história natural da doença óssea associada ao mieloma e a outras neoplasias que infiltram os ossos. São drogas geralmente bem toleradas e associadas a efeitos colaterais mínimos quando administradas por curtos períodos. Entretanto, o pamidronato (Aredia) e o ácido zoledrônico (Zometa) são administrados mensalmente ao longo de meses ou anos nos pacientes portadores de mieloma múltiplo, e, recentemente, complicações que parecem relacionadas ao uso prolongado da medicação têm sido descritas. ${ }^{1-5}$ Dentre elas, a necrose avascular da mandíbula é um evento raro, mas potencialmente grave.

A osteonecrose é relativamente comum na mandíbula, pois o local é freqüentemente exposto ao ambiente externo quando de exodontias, grandes procedimentos dentários e durante a higiene oral. Outro fator contribuinte para a dificuldade de cicatrização pode ser a particular vascularização da mandíbula através de artérias terminais, já que a hipóxia tecidual inibe a síntese de colágeno, a proliferação fibroblástica e o estímulo à vascularização. ${ }^{2}$

A terapia da osteonecrose é variável e as múltiplas abordagens incluem o uso de analgésicos sistêmicos, debrida- mento cirúrgico, uso prolongado de antibióticos e oxigenioterapia hiperbárica (neste caso, experiência limitada e controversa). ${ }^{1,4}$

\section{Conclusão}

A osteonecrose da mandíbula é uma complicação rara e de difícil manejo da terapia com bisfosfonatos. A possível contribuição de outros agentes envolvidos no tratamento do mieloma (corticóides, talidomida) permanece indeterminada. ${ }^{6}$

Os pacientes que recebem bisfosfonatos devem ser orientados a evitar procedimentos dentários. Caso requeiram estas intervenções devem ser observados de perto. Diante de qualquer sintoma referido à mandíbula devem ter exames de imagem realizados e, se confirmado o quadro, ter a terapia com bisfosfonatos interrompida.

\section{Abstract}

We report the occurrence of jaw necrosis associated to pamidronate (Aredia) therapy in a patient undergoing multiple myeloma treatment. Although it is not possible to prove definitively the link between bisphosphonate therapy and jaw osteonecrosis, the association of multiple myeloma with severe immunosuppression, prolonged bisphosphonate therapy and the occurrence of jaw necrosis, suggest a relationship. Hematologists should be aware of this potentially serious complication in multiple myeloma patients receiving longterm treatment with pamidronate. Rev. bras. hematol. hemoter. 2005;27(3):221-222..

Key words: Multiple myeloma; osteonecrosis of the jaw; pamidronate.

\section{Referências Bibliográficas}

1. Lugassy G, Shaham R, Nemets A et al. Severe osteomyelitis of the jaw in long-term survivors of multiple myeloma: a new clinical entity. Am J Med 2004;117:440-1.

2. Began JV, Murillo J, Jimenez Y et al. Avascular jaw osteonecrosis in association with cancer chemotherapy: series of 10 cases. J Oral Pathol Med 2005;34:120-3.

3. Kyle AR, Rajlumar SV. Multiple myeloma. N Engl J Med 2004; 351 : 1.860-73.

4. Vannucchi AM, Ficarra G, Antonioli E et al. Osteonecrosis of the jaw associated with zoledronate therapy in a patient with multiple myeloma. Br J Haematol 2005;128:738.

5. Ruggiero SL, Mehrotra B, Rosenberg TJ et al. Osteonecrosis of the jaws associated with the use of bisphosphonates: a review of 63 cases. J Oral Maxillogac Surg 2004;62:527-34.

6. Altundag K, Altundag O, Gundeslioglu O. Multiple myeloma. N Engl $\mathrm{J}$ Med 2005;352:840.

Avaliação: Editor e dois revisores externos.

Conflito de interesse: não declarado

Recebido: 16/07/2005

Aceito após modificações: 15/08/2005 